\title{
BMJ Open Community preparedness for emergency: a cross-sectional survey of residents in Heilongjiang of China
}

Weilan Xu, ${ }^{1}$ Yanhua Hao, ${ }^{1,2}$ Qunhong Wu, ${ }^{1,2}$ Ning Ning, ${ }^{1,2}$ Jia You, ${ }^{1}$ Chaojie Liu, ${ }^{3}$ Mingli Jiao, ${ }^{1,2}$ Lijun Gao, ${ }^{1,2}$ Zheng Kang, ${ }^{1,2}$ Libo Liang, ${ }^{1,2}$ Hong Sun, ${ }^{1,2}$ Yu Cui, ${ }^{1,2}$ Ye Li, ${ }^{1,2}$ Xiaonan Han, ${ }^{1}$ Xin Fang, ${ }^{1}$ Xiyan Zhao, ${ }^{1}$ Man Hu, ${ }^{1}$ Ding Ding, ${ }^{1}$ Hao Gao, ${ }^{1}$ Jun $\mathrm{Lu}^{4}$

To cite: Xu W, Hao Y, Wu Q, et al. Community preparedness for emergency: a cross-sectional survey of residents in Heilongjiang of China. BMJ Open 2015;5: e008479. doi:10.1136/ bmjopen-2015-008479

- Prepublication history for this paper is available online. To view these files please visit the journal online (http://dx.doi.org/10.1136/ bmjopen-2015-008479).

WX, NN and JY contributed equally.

Received 13 April 2015 Revised 16 September 2015 Accepted 13 October 2015

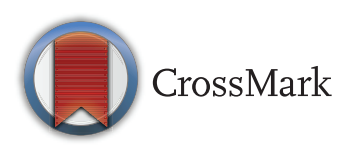

For numbered affiliations see end of article.

Correspondence to Professor Yanhua Hao; hyhyjw@126.com and Professor Qunhong Wu, wuqunhong@163.com

\section{ABSTRACT}

Objective: This article aims to identify factors that shape the knowledge, attitudes and behaviours of community residents in China's Heilongjiang province towards emergency preparedness. Findings of such a study may provide evidence to support the development of effective public risk communication strategies and education campaigns.

Design: A cross-sectional household questionnaire survey was conducted in Heilongjiang province in 2014.

A stratified cluster sampling strategy was employed to select study participants. The questionnaires were administered using face-to-face interviews. 2800 questionnaires were completed, among which 2686 $(95.9 \%)$ were considered valid for data analyses. A multivariate logistic regression model was adopted to identify the extent to which the independent variables were associated with emergency preparedness.

Results: Fewer than 5\% respondents were well prepared for emergency. Over half $(52 \%)$ of poorly prepared respondents did not know what to do in emergency; women (OR=1.691), higher household income (OR ranging from 1.666 to 2.117 ), previous experience with emergency ( $\mathrm{OR}=1.552)$, higher levels of knowledge about emergency $(\mathrm{OR}=2.192)$, risk awareness $(0 R=1.531)$, self-efficacy $(0 R=1.796)$, as well as positive attitudes towards emergency preparedness $(\mathrm{OR}=2.265)$ were significant predictors for emergency preparedness. Neither educational attainment nor exposure to awareness-raising entered into the logic regression model as a significant predictor for emergency preparedness.

Conclusions: The level of emergency preparedness in Heilongjiang residents is very low, which is linked with poor knowledge and attitudes of the residents towards emergency preparedness. Future emergency awareness campaigns should be more focused and tailored to the needs of intended audience, taking into consideration of their usual source of information and knowledge in relation to emergency.

\section{INTRODUCTION}

The past 10 years have seen a $14 \%$ rise in affected populations and a $39 \%$ rise in

\section{Strengths and limitations of this study}

The questions measuring awareness and preparatory behaviours for emergency were intentionally broad, covering four broad types of events, which may have contributed towards unclear or vague responses from some participants. Owing to limited resources, the survey was conducted only in Heilongjiang province. Despite these limitations, this study provides important information for understanding resident preparedness behaviours and evidence to support the development of effective public risk communication and education campaigns.

deaths as a result of disasters, both natural and manmade, according to the World Disasters Report 2012. ${ }^{1}$ In 2014, 210 million people were affected by disasters across the globe. China is one of a number of countries particularly vulnerable to natural disasters. It was estimated that, during February 2015 alone, 238000 people in China were affected by natural disasters and more than 2000 people needed emergency assistance. The direct economic loss reached $¥ 230$ million. ${ }^{2}$

Effective responses to disasters depend not only on the strong leadership and coordinated actions of governmental agencies and professional bodies, but also on the efforts of local residents. Emergency preparedness and early self-help efforts of local residents are usually critical for disaster victim survival. ${ }^{3}$

Extensive studies have investigated the effectiveness of professional responses to emergency events ${ }^{4}$; however, there is paucity in the literature documenting individual and community preparedness for emergencies. ${ }^{5}$ In a 2009 national survey conducted by the US Federal Emergency Management Agency (FEMA), $57 \%$ of respondents reported having an emergency kit prepared within the 
home. ${ }^{6}$ The Council for Excellence in Government found that one-third $(32 \%)$ of US residents took no steps to prepare for potential emergencies, with lack of awareness, beliefs and resources (time, knowledge, money) being cited as the main reasons. ${ }^{78}$ The level of individual emergency preparedness in China is even lower. A study of 2000 Beijing residents in 2009 revealed that $2.5 \%$ had prepared emergency kits, ${ }^{9}$ similar to the finding $(2.2 \%)$ of another study conducted in Shanxi province. $^{10}$

Low levels of public awareness and failure to prepare present challenges for emergency response management. ${ }^{3}$ This study aims to identify factors that may shape the knowledge, attitudes and behaviours of community residents in China's Heilongjiang province towards emergency preparedness. Findings of such a study may provide evidence to support the development of effective public risk communication and education campaigns.

\section{METHODS}

\section{Study population}

A cross-sectional household questionnaire survey was conducted in Heilongjiang province between September and October 2014. Heilongjiang is located in northeast China, with a population of over 38 million. In 2014, the Gross domestic product per capita in Heilongjiang reached $¥ 39226.4$, ranking in the lowest range of all provinces. $^{14}$

A stratified cluster (in terms of demographic and social economic diversity) sampling strategy was used to select study participants. Five major municipalities in Heilongjiang (Harbin, Qiqihar, Mudanjiang, Jiamusi, Daqing) were involved in the study. One urban district and one rural county of the five municipalities were randomly selected. Two communities/villages within each selected district/county were sampled. All households were identified as the participants for survey and each household identified one adult member to complete the questionnaire. The questionnaires were administered through face-to-face interviews, each of which took on average $20 \mathrm{~min}$ to complete. A total of 2800 questionnaires were completed, among which 2686 (95.9\%) were valid for data analyses.

\section{Data collection}

Trained postgraduate students from the school of public health of Harbin Medical University collected data. Those students spoke the same dialect as those interviewed, were involved in the development of the questionnaire (eg, literature review and identification of relevant theories), conducted a pilot study in a convenience sample $(n=110)$ and a random cluster sample $(n=468)$ to test the validity and reliability of questionnaire, ${ }^{12}$ as well as participated in several research workshops prior to embarking on the full-scale survey. One experienced researcher supervised the data collection activities in each community.

\section{Measurement}

The questionnaire was developed based on an emergency preparedness model proposed by Jessica Enders. ${ }^{13}$ A total of 50 items were included in the questionnaire (excluding demographic and social economic characteristics), which yielded a Cronbach's $\alpha$ of 0.847 and a Spearman-brown formula of 0.884, demonstrating acceptable internal reliability and validity.

\section{Dependent variable}

Emergency preparedness was the outcome measure (dependent variable); defined as the necessary actions for an emergency. In this study, we measured emergency preparedness by asking participants what items they had in an ideal emergency supplies checklist. ${ }^{14}$ The 'ideal' checklist consists of 20 commonly used items in case of an emergency defined by the public education 'ready' programme in the USA and the Manual for All Citizens to Prevent Disaster edited by Ministry of Civil Affairs of the People's Republic of China. ${ }^{8}{ }^{15}$ Those who possessed all or more than the five essential items (3-day supply of food and water, first aid kit, battery-powered radio, flashlight, and extra batteries) ${ }^{16}$ were categorised as well prepared.

\section{Independent variable}

There are several steps involved between individual receiving information and then acting based on the information received. Enders ${ }^{13}$ summarised six major factors that may determine/change the course of actions during the process.

1. Demographic and social economic characteristics of participants, such as gender, age, marital status, education background, residential location and household income.

2. Previous experience coping with an emergency.

3. Emergency cognition-knowledge in relation to three types of emergency events was tested in this study using 16 statements: natural disaster (eg, shelter location and self-saving principles following an earthquake), man-made disaster (eg, evacuation routes and methods in household fire), and public health emergency (eg, symptoms, route of transmission, and preventive measures of respiratory infectious diseases; food handling and poisoning rescue measures). Respondents were asked to choose one answer for each of the statements: $1=$ correct, $2=$ =incorrect, 3=don't know. One point was awarded for each correct response.

4. Risk awareness-we asked participants to rate on a five-point Likert scale about the likelihood of occurrence of emergency events in relation to natural disaster (earthquake), accidental disaster (fire), public health (communicable disease) and social safety events (terrorism).

5. Attitudes towards emergency preparedness-respondents were asked to rate their attitudes and beliefs towards emergency preparedness. Five questions were 
asked for this purpose, each being assessed on a fivepoint Likert scale (strongly agree, agree, neutral, disagree, strongly disagree). The questions were: 'I do not believe preparation will make any difference in emergency events'; 'I am very interested in emergency-related information/news'; 'I pay special attention to all kinds of warnings issued by governmental authorities'; 'I often discuss with my friends and family members about emergency response'; 'I have confidence on governments in responding to emergencies'.

6. Self-efficacy-respondents were asked to rate their own ability to respond to emergencies and mitigate risks on a five-point Likert scale (ranging from totally disagree to totally agree).

Those considered factors can find their foundations from a few theories. For example, theory of rational action (TRA), ${ }^{17}$ which believes that human behaviours are consciously influenced by individual attitudes; Bandera's self-efficacy theory, which addresses the confidence and ability of a person to adjust and control his/ her own behaviours; Tran-theoretical model, which emphasises the importance of both internal and external factors for driving changes in human behaviour ${ }^{18}$ and KAP theory, which puts knowledge, attitudes, belief and action in sequence with each serving as a precondition for the latter one. ${ }^{19}$

\section{Statistical analysis}

The outcome (dependent) variable was treated as a nominal measure: 'well prepared' versus 'poorly prepared'.

We calculated dimensional scores for knowledge, risk awareness, attitudes towards preparedness and selfefficacy, and then transformed them into a nominal measure: 'above average' versus 'on/below average'.

$\chi^{2}$ Tests were performed to determine the differences in emergency preparedness across different levels of independent variables. A multivariate logistic regression model was adopted to identify the extent to which the independent variables were associated with outcome measures (preparedness). An enter regression based on the maximum likelihood estimation method was used, with an enter/exit criterion $(\alpha)$ of $0.05 / 0.10$.

All statistical analyses were performed using SPSS V.19.0.

\section{RESULTS}

\section{Participant characteristics}

Slightly less than half $(48 \%)$ of respondents were in the age between 31 and 50 years. Women comprised $56 \%$ of the respondents. Most (59\%) respondents lived in an urban community. The majority $(79 \%)$ were married at the time of the survey. More than half of respondents completed senior high school level of education. A household monthly income of between ¥2000 and $¥ 4999$ accounted for $53 \%$ of all respondents (table 1).
Less than $5 \%(133 / 2686)$ of respondents were rated as 'well-prepared', that is possessing all five essential emergency items, while more than $9.5 \%$ of respondents did not possess any emergency items at all. Emergency preparedness was found to be associated with gender $\left(\chi^{2}=4.846, p=0.028\right)$, age $\left(\chi^{2}=6.979, p=0.031\right)$, residential location $\left(\chi^{2}=4.302, \quad \mathrm{p}=0.038\right)$, education $\left(\chi^{2}=6.260\right.$, $\mathrm{p}=0.044)$, household income $\left(\chi^{2}=9.526, \mathrm{p}=0.009\right)$, past experience with emergency $\left(\chi^{2}=10.910, p=0.001\right)$, exposure to awareness-raising $\left(\chi^{2}=4.236, \mathrm{p}=0.040\right)$, as well as knowledge $\quad\left(\chi^{2}=25.583, \quad \mathrm{p}<0.001\right), \quad$ risk awareness $\left(\chi^{2}=7.646, \mathrm{p}=0.006\right)$, attitudes $\left(\chi^{2}=33.895, \mathrm{p}<0.001\right)$ and self-efficacy $\left(\chi^{2}=18.926, p<0.001\right)$. Women, older people, urban residents and those who completed senior high schools and had a higher household income were more likely to be rated as well prepared. The respondents who had previous experience of emergencies and exposure to awareness-raising had a higher percentage of well prepared than those who did not. Higher levels of knowledge, risk awareness, self-efficacy and positive attitudes towards emergency preparedness were positively correlated with preparedness outcomes. Marital status and living with a child (under 18 years of age) were not found to be associated with emergency preparedness (table 1).

\section{Logistic regression analysis on emergency preparedness}

In the multivariate logistic regression model, 11 independent variables were included which had statistical significance in $\chi^{2}$ test $(p<0.05)$. Seven independent variables were identified as significant predictors for emergency preparedness. Women $(\mathrm{OR}=1.691)$ and those who had a higher household income (OR ranging from 1.666 to 2.117 ) were more likely to be rated well prepared. Previous experience with emergency $(\mathrm{OR}=1.552)$, higher levels of knowledge about emergency $(\mathrm{OR}=2.192)$, risk awareness $(\mathrm{OR}=1.531)$, selfefficacy ( $\mathrm{OR}=1.796)$, as well as positive attitudes towards emergency preparedness $(\mathrm{OR}=2.265)$ were also significant predictors for emergency preparedness; however, neither educational attainments nor exposure to awareness-raising featured in the logic regression model as a significant predictor for emergency preparedness (table 2).

\section{Reasons of poor preparation for emergency}

Lack of awareness and knowledge about emergency was cited by the respondents as the most important reasons of poor preparation for emergency (figure 1). More than half $(51.7 \%)$ of poorly prepared respondents did not know what to do, while over $30 \%$ simply disregarded emergency preparation as an issue that affected them. More than $20 \%$ of respondents preferred to leave emergency preparedness in the hands of professional workers $(22.7 \%)$, blame the government and media for limited information disclosure $(21.8 \%)$, or/and maintain optimistic perspective $(23.9 \%)$, hoping that any disaster will not befall them. Interestingly, $<15 \%$ of respondents 
Table 1 Characteristics of respondents and emergency preparedness outcomes $(n=2686)$

\begin{tabular}{|c|c|c|c|c|}
\hline Variables & $\begin{array}{l}\text { Respondents } \\
\mathrm{n}(\%)\end{array}$ & $\begin{array}{l}\text { Well-prepared } \\
\mathrm{n}(\%)\end{array}$ & $\chi^{2}$ & p Value \\
\hline Gender & & & 4.846 & 0.028 \\
\hline Male & $1177(43.9)$ & $46(3.9)$ & & \\
\hline Female & $1509(56.1)$ & $87(5.8)$ & & \\
\hline Age & & & 6.979 & 0.031 \\
\hline $18-30$ & $717(26.7)$ & $30(4.2)$ & & \\
\hline $31-50$ & $1281(47.7)$ & $56(4.4)$ & & \\
\hline $51+$ & $688(25.6)$ & $47(6.8)$ & & \\
\hline Residential location & & & 4.302 & 0.038 \\
\hline Urban & $1586(59.1)$ & $90(5.7)$ & & \\
\hline Rural & $1100(40.9)$ & $43(3.9)$ & & \\
\hline Marital status & & & 0.244 & 0.621 \\
\hline Married & $2115(78.7)$ & $107(5.1)$ & & \\
\hline Others & $571(21.3)$ & $26(4.6)$ & & \\
\hline Educational attainment & & & 6.260 & 0.044 \\
\hline$\leq$ Junior high school & $1260(46.9)$ & $49(3.9)$ & & \\
\hline Senior high school & $644(24.0)$ & $41(6.4)$ & & \\
\hline University & $782(29.1)$ & $43(5.5)$ & & \\
\hline Household monthly income ( $¥)$ & & & 9.526 & 0.009 \\
\hline 0-1999 & $853(31.7)$ & $28(3.3)$ & & \\
\hline 2000-4999 & $1409(52.5)$ & $75(5.3)$ & & \\
\hline $5000^{+}$ & $424(15.8)$ & $30(7.1)$ & & \\
\hline Living with a child under 18 years & & & 0.585 & 0.444 \\
\hline No & $1258(46.84)$ & $58(4.6)$ & & \\
\hline Yes & $1428(53.16)$ & $75(5.3)$ & & \\
\hline Previous experience with emergency & & & 10.910 & 0.001 \\
\hline No & $2106(78.4)$ & $89(4.2)$ & & \\
\hline Yes & $580(21.6)$ & $44(7.6)$ & & \\
\hline Exposure to awareness raising during the past year & & & 4.236 & 0.040 \\
\hline No & $2056(76.5)$ & $92(4.5)$ & & \\
\hline Yes & $630(23.5)$ & $41(6.5)$ & & \\
\hline Knowledge about emergency & & & 25.583 & 0.000 \\
\hline On/below average & $1301(48.4)$ & $36(2.8)$ & & \\
\hline Above average & $1385(51.6)$ & $97(7.0)$ & & \\
\hline Risk awareness & & & 7.646 & 0.006 \\
\hline On/below average & $1444(53.8)$ & $56(3.9)$ & & \\
\hline Above average & $1242(46.2)$ & $77(6.2)$ & & \\
\hline Attitudes towards preparedness & & & 33.895 & 0.000 \\
\hline On/below average & $1307(48.7)$ & $32(2.4)$ & & \\
\hline Above average & $1379(51.3)$ & $101(7.3)$ & & \\
\hline Self-efficacy & & & 18.926 & 0.000 \\
\hline On/below average & $1652(61.5)$ & $58(3.5)$ & & \\
\hline Above average & $1034(38.5)$ & 75 (7.3) & & \\
\hline
\end{tabular}

attributed their poor preparedness to limited access to resources, such as time, money and personal ability.

Further data exploration (table 3) revealed that mass media was the major contributor to emergency knowledge, with more than $77.7 \%$ respondents being exposed to it; closely followed by personal communications $(33.9 \%)$. By contrast, educational programmes were an information source for only $15.8 \%$ (through community emergency education programmes) to $22.1 \%$ (through school education) of respondents. Most respondents $(90 \%)$ had never participated in emergency response exercises.

\section{DISCUSSION}

The level of emergency preparedness in Heilongjiang residents is very low: fewer than $5 \%$ of respondents reported having essential emergency supplies in hands; and $9.5 \%$ possessed no items in the emergency supplies checklist (20 specific items). Such a low level of emergency preparedness has also been found in studies undertaken elsewhere in China. ${ }^{20}{ }^{21}$ Despite differences in data collection methods, it is evident that the US populations have a much higher level of emergency preparedness compared with Chinese populations. FEMA reported that $57 \%$ of US citizens have emergency 
Table 2 Logistic regression analysis on emergency preparedness

\begin{tabular}{|c|c|c|c|c|c|}
\hline \multirow{2}{*}{$\begin{array}{l}\text { Variables } \\
\text { Gender }\end{array}$} & \multirow[t]{2}{*}{ Walds } & \multirow[t]{2}{*}{ p Value } & \multirow[t]{2}{*}{ OR } & \multicolumn{2}{|l|}{$95 \% \mathrm{Cl}$} \\
\hline & & & & & \\
\hline $\begin{array}{l}\text { Female } \\
\text { Male (reference) }\end{array}$ & 7.495 & 0.006 & 1.691 & 1.161 & 2.462 \\
\hline \multicolumn{6}{|l|}{ Age } \\
\hline \multicolumn{6}{|l|}{ 18-30 (reference) } \\
\hline $30-50$ & 0.093 & 0.760 & 0.930 & 0.582 & 1.484 \\
\hline $51+$ & 3.492 & 0.062 & 1.626 & 0.977 & 2.707 \\
\hline \multicolumn{6}{|l|}{ Residential location } \\
\hline Rural & 0.002 & 0.964 & 1.011 & 0.623 & 1.641 \\
\hline Urban (reference) & & & & & \\
\hline \multirow{2}{*}{\multicolumn{6}{|c|}{ Education }} \\
\hline & & & & & \\
\hline Senior high school & 2.327 & 0.127 & 1.471 & 0.896 & 2.415 \\
\hline University & 0.584 & 0.445 & 1.233 & 0.720 & 2.112 \\
\hline \multicolumn{6}{|l|}{ Household monthly income ( $¥)$} \\
\hline \multicolumn{6}{|l|}{ 0-1999 (reference) } \\
\hline 2000-4999 & 4.152 & 0.042 & 1.666 & 1.020 & 2.722 \\
\hline $5000+$ & 6.031 & 0.014 & 2.117 & 1.163 & 3.851 \\
\hline \multicolumn{6}{|c|}{ Previous experience with emergency } \\
\hline $\begin{array}{l}\text { Yes } \\
\text { No (reference) }\end{array}$ & 4.929 & 0.026 & 1.552 & 1.053 & 2.286 \\
\hline \multicolumn{6}{|c|}{ Exposure to awareness-raising in last year } \\
\hline $\begin{array}{l}\text { Yes } \\
\text { No (reference) }\end{array}$ & 0.847 & 0.358 & 0.827 & 0.552 & 1.239 \\
\hline \multicolumn{6}{|l|}{ Knowledge about emergency } \\
\hline $\begin{array}{l}\text { Above average } \\
\text { On/below average (reference) }\end{array}$ & 13.978 & 0.000 & 2.192 & 1.453 & 3.308 \\
\hline \multicolumn{6}{|l|}{ Risk awareness } \\
\hline $\begin{array}{l}\text { Above average } \\
\text { On/below average (reference) }\end{array}$ & 5.285 & 0.022 & 1.531 & 1.065 & 2.202 \\
\hline \multicolumn{6}{|l|}{ Emergency attitude } \\
\hline $\begin{array}{l}\text { Above average } \\
\text { On/below average (reference) }\end{array}$ & 14.196 & 0.000 & 2.265 & 1.480 & 3.465 \\
\hline \multicolumn{6}{|l|}{ Self-efficacy } \\
\hline $\begin{array}{l}\text { Above average } \\
\text { On/below average (reference) }\end{array}$ & 9.500 & 0.002 & 1.796 & 1.238 & 2.606 \\
\hline Constants & 54.929 & 0.000 & 0.003 & & \\
\hline
\end{tabular}

supplies prepared and ready to be used solely in the case of a disaster. ${ }^{6}$

As found in the literature, poor knowledge and attitudes towards emergency preparedness are the major factors that have contributed to the low level of community preparedness outcomes ${ }^{22}$ significant associations between preparedness outcomes and individual knowledge and attitudes have been demonstrated in the $\chi^{2}$ tests, the multivariate regression model, and the subjective perception survey in this study. More than half of the poorly prepared respondents simply did not know what to do.

Knowledge and attitudes towards emergency preparedness were found to have the greatest OR $(>2)$ in the multivariate regression model on preparedness outcome. Indeed, knowledge and attitudes are regarded as a key driver of human behaviours in several behavioural theories. ${ }^{23}$
Although financial capability remains as a significant factor influencing emergency preparedness, the study participants perceived limited resources and ability to prepare as a contributor for a very small proportion $(<15 \%)$ of poor preparedness outcomes. Nevertheless, there is an increased need for help in emergency for the households with low income. ${ }^{24} 25$

Effective education and exercise can help community residents recognise and identify hazards to improve their understanding about how to respond. ${ }^{26} 27$ This study showed that mass media is perhaps the most important channel for people to obtain information about emergency. It is important to note that educational attainments and exposure to awareness-raising were not found to be associated with emergency preparedness. Obviously, educational campaigns need to be carefully designed and tailored to the needs of their audiences. 
Figure 1 Reasons of poor preparation for emergency.
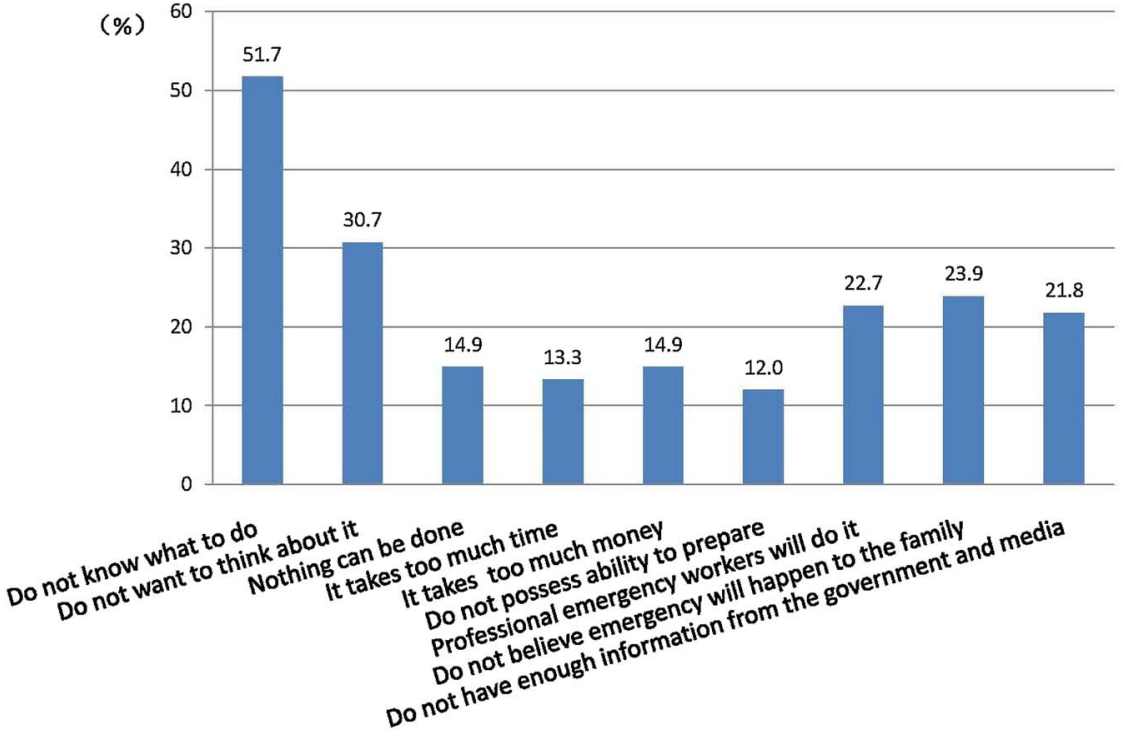

Reasons

An effective communication and education programme should target the most important audience in a way that is most appropriate to the audience. Women, for example, may play a critical role in community emergency preparedness. ${ }^{28} 29$ This study likewise found that women are more likely to be prepared for emergencies than men. The finding is somehow different from that of the FEMA study, ${ }^{6}$ in which US men were reported having a higher level of emergency preparedness. Such inconsistency may have actually reflected cultural differences: in China, women are usually responsible for shopping and housing arrangements, and thus determine what items to be stored at home.

Risk awareness should also be a key element in emergency education programmes. Several studies confirmed that individuals with low risk awareness are less likely to respond to warnings and undertake preparatory actions compared to those with higher risk awareness. ${ }^{30-32}$ Risk awareness plays an important role at the early stage of the continuum from information attainment to behavioural changes. ${ }^{33}$ It encourages people to seek information. Gisela Wachinger proposed a heuristic framework to understand the relationship between risk perceptions and individual behaviours. ${ }^{34}$ Three factors may mediate the relationship: experience and motivation, trust and

\begin{tabular}{|c|c|c|}
\hline Sources of knowledge & $\begin{array}{l}\text { Number of } \\
\text { respondents }\end{array}$ & $\begin{array}{l}\text { Per } \\
\text { cent }\end{array}$ \\
\hline Mass media & 2087 & 77.7 \\
\hline Personal communication & 911 & 33.9 \\
\hline School education & 593 & 22.1 \\
\hline $\begin{array}{l}\text { Community education } \\
\text { programme }\end{array}$ & 424 & 15.8 \\
\hline $\begin{array}{l}\text { Emergency response } \\
\text { exercise }\end{array}$ & 279 & 10.4 \\
\hline
\end{tabular}

responsibility, and ability (economic and personal condition). We found that past experience with emergencies is associated with improved preparedness. It is understandable that those who have experienced with emergency events may have increased awareness of the importance of preparedness. ${ }^{35}$ In general, they tend to be more proactive in obtaining knowledge and information and taking preparatory actions ${ }^{36-41}$; however, those who have not experienced personal damage during a hazardous event are less likely to believe that a future event may bring harm to them, which may jeopardize their preparatory efforts. ${ }^{42}$ A survey conducted in Gansu reported that past experience with disastrous events was associated with risk perceptions, but the perceptions failed to translate into preparatory actions. ${ }^{43}$ Some researchers argue that there is not necessarily a direct link between awareness, risk perception and desired preparation or behavioural response. ${ }^{27}$ Perceived coping ability (self-efficacy) may mediate the link between risk awareness and emergency preparedness outcomes. External conditions may also alter the course of actions. ${ }^{44}$ Emergency response exercises could help build the link between risk awareness and preparatory actions. $^{13}$

\section{Limitation}

This study has several limitations. The questions measuring awareness and preparatory behaviours for emergency were intentionally made broad, covering four types of events (natural disaster, public health emergency, human-made accidence, and social security event). The broad notion and non-specific events may cause unclear or vague responses from some participants, especially in those with low levels of education. However, the questionnaires were administered through face-to-face interviews and all of the interviewers had been made aware of this potential problem to minimise such a bias. Owing to limited resources, the survey was 
conducted only in Heilongjiang province. In this article, we examined potential factors that are associated with preparedness outcomes; further studies are needed to explore the mechanisms of the links between those factors and preparedness outcomes.

\section{Conclusion}

The level of emergency preparedness in Heilongjiang residents is very low $(<5 \%)$, which is linked with a lack of knowledge and resident attitudes towards emergency preparedness. Future education and communication campaigns should be more focused and tailored to the needs of intended audience, taking into consideration of their usual sources of information and knowledge in relation to emergency preparedness. A variety of strategies should be taken to increase community risk awareness, including emergency training and exercise; mobilisation of volunteers; emergency day event for publicising purpose; and mass media (web, TV, radio, etc) campaigns. Women may become the major audience because they are responsible for housing arrangements and are more likely to become well prepared than men. It is also important to emphasize the translation process from increased awareness into preparatory actions, possibly through emergency response exercises. Currently, only $10 \%$ of Heilongjiang residents participated in emergency response exercises, falling far short of expectations.

\author{
Author affiliations \\ ${ }^{1}$ School of Health Management, Harbin Medical University, Harbin, \\ Heilongjiang, China \\ ${ }^{2}$ Collaborative Innovation Center of Social Risks Governance in Health, China \\ ${ }^{3}$ School of Psychology and Public Health, La Trobe University, Melbourne, \\ Victoria, Australia \\ ${ }^{4}$ Fudan University, Shanghai, China
}

Acknowledgements The authors are grateful to the support of local officials from sampled municipalities. They thank all of the participants and the postgraduate students who collected the data. Mr Adamm Ferrier proofread the revised manuscript and corrected language errors.

Contributor WX participated in design of the research, conducted the survey and collected the data, and conducted analysis of the data, draft and edit the manuscript. YH and QW were responsible for the overall design of the research, organized and conducted the survey, designed the analysis frameworks, drafted and edited the manuscript. NN, JY, GL and MJ participated in design of the research, conducted survey and collected the data, drafted and edited the manuscript. LG, ZK, LL, HS, YC, YL and JL participated in design of the research, organized and conducted the survey, and edited the manuscript; XH, XF, XZ, MH, DD and HG participate in literature search, conducted the survey and collected the data, and edited the manuscript.

Funding This study was funded by the National Natural Scientific Fund of China $(71173064,71473065)$ and the Ministry of Health Public Benefit Fund for Health Sector (201002028).

Competing interests None declared.

Ethics approval The Medical Research Ethics Committee of Harbin Medical University.

Provenance and peer review Not commissioned; externally peer reviewed.

Data sharing statement No additional data are available.
Open Access This is an Open Access article distributed in accordance with the Creative Commons Attribution Non Commercial (CC BY-NC 4.0) license, which permits others to distribute, remix, adapt, build upon this work noncommercially, and license their derivative works on different terms, provided the original work is properly cited and the use is non-commercial. See: http:// creativecommons.org/licenses/by-nc/4.0/

\section{REFERENCES}

1. WHO. Emergency and humanitarian action. Vulnerable on the rise. http://www.searo.who.int/entity/emergencies/data/en (accessed 9 Mar 2015)

2. China National Commission for Disaster Reduction. China national natural disaster status publication on Feb, 2015. http://www.jianzai. gov.cn//DRpublish/jzdt/0000000000007756.html (accessed 9 Mar 2015).

3. Liu CJ, Robinson P. Better organisation of volunteers in disaster settings is needed: lessons for all from China. Aust N Z J Public Health 2013;37:595-6.

4. FEMA. National Preparedness Report 2013. http://www.llis.dhs.gov/ sites/default/files/npr2013_final. pdf (accessed 13 Mar 2015).

5. Zhang WQ, Liu CJ, Sun TS, et al. Physical and mental health status of soldiers responding to the 2008 Wenchuan earthquake. Aust N Z J Public Health 2011;35:207-11.

6. FEMA. Personal Preparedness in America: Findings from the 2009 Citizen Corps National Survey. http://www.citizencorps.gov/ready/ research.shtm (accessed 11 Mar 2015).

7. Li HM, Ma J. America "Ready" campaign and its enlightenment to earthquake disaster reduction of China. Recent Dev World Seismol 2010;11:12-18.

8. The council for excellence in government. Are we ready? Introducing the public readiness index: a survey-based tool to measure the preparedness of individuals, families and communities. http://www. citizencorps.fema.gov/downloads/pdf/ready/pri_report.pdf (accessed 11 Mar 2015).

9. Chen Y. Knowledge and skills investigation of individual response to public health emergencies in Beijing Chaoyang District. Chin Center Dis Control Prev 2009;6:1-4.

10. Cai $\mathrm{Y}, \mathrm{Tao} \mathrm{CX}$, Chen $\mathrm{YL}$, et al. Analysis of the intervention effect to knowledge and skills of individual response to public health emergencies in Shanxi province. Chin Prev Med 2014;15:28-32.

11. Heilongjiang municipal GDP and per capita GDP ranking 2014. http://www.360doc.com/content/15/0320/14/502486 456688931. shtml (accessed 2 Apr 2015).

12. Zhang WJ, Hao $\mathrm{YH}, \mathrm{Wu} \mathrm{QH}$, et al. Establishment and evaluation of the public's emergency preparedness measurement scale. Chin $J$ Public Health 2014;5:650-2.

13. Enders J. Measuring community awareness and preparedness for emergency. Aust J Emerg Manag. http://www.em.gov.au/ Documents/Measuring_community_awareness_and_preparedness_ for emergencies.pdf (accessed 11 Mar 2015)

14. Levac J, Toal-Sullivan D, O'Sullivan TL. Household emergency preparedness: a literature review. J Community Health 2012;37:725-33.

15. Ministry of Civil Affairs of the People's Republic of China. The manual for all citizens to prevent disaster. Beijing: The science press, 2010:9.

16. U.S. Department of Homeland Security. Increasing Citizen Preparedness Through Applied Research Proceedings of a Research Roundtable. February 2007. http://www.citizencorps.fema. gov/downloads/pdf/ready/Research\%20Roundtable\%202007\% 20FINAL.pdf (accessed 9 Mar 2015).

17. Duang YT, Jiang GR. Review of theory of rational action. Adv Psychol Sci 2008;16:315-20.

18. Zhang AQ. Self-efficacy and organization networking. Organizational Behavior. Beijing, BJ: China Machine Press, 2013:126.

19. Yun-hong L. Application of practice model of knowledge-attitude-belief in the health education for the patients with essential hypertension. J Qilu Nurs 2007;3:5.

20. Li Y, Dong XM, Wang SY, et al. Consciousness and abilities on health emergency and the roles of emergency response among public at the communities. China J Epidemiol 2013;10:993-7.

21. Ning Y, Tao MX, Hu JF, et al. Factors affecting the knowledge of disastrous event response among residents in Shaanxi province. Chin Prev Med 2011;6:473-6.

22. Annika L. How much can a KAP survey tell us about people's knowledge, attitudes and practices? Some observations from medical anthropology research on malaria in pregnancy in Malawi. Anthropol Matters J 2009;11:1-13. 
23. Vaughan E, Tinker T. Effective health risk communication about pandemic influenza for vulnerable populations. Am J Public Health 2009;99(Suppl 2):S324-32.

24. FEMA. Business Continuity and Disaster Preparedness Planning Patterns and Findings from Current Research. Citizen preparedness review. Winter 2011:8.

25. Abrahamson V, Raine R. Health and social care responses to the Department of Health Heatwave Plan. J Public Health (Oxf) 2009;31:478-89.

26. Xing JJ. Study on the architecture and key elements of emergency preparedness culture. J Saf Sci Technol 2010; 10:82-6.

27. Haynes K, Barclay J, Pidgeon N. Whose reality counts? Factors effecting the perception of volcanic risk. J Volcanol Geotherm Res 2008;172:259-72.

28. You J, Hao YH, Gao LJ, et al. Study on the level of emergency items preparedness and its influencing factors among the seven college students in Heilongjiang Province. Chin J Prev Med 2015;16:11-14

29. Karinanci N, Bahatt H, Gulay D. Impact of a community disaster awareness training program in Turkey: Does it influence hazard-related cognitions and preparedness behaviors? Soc Behav Pers 2005;33:243-58.

30. Burke S, Bethel JW, Britt AF. Assessing disaster preparedness among Latino migrant and seasonal farm workers in eastern North Carolina. Int J Environ Res Public Health 2012;9: 3115-33.

31. Bichard E, Kazmierczak A. Are homeowners willing to adapt to and mitigate the effects of climate change? Climate Change 2012;112:633-54.

32. Han X, Ding YB, Zhang HW, et al. Prevention of sudden disaster risk and public participation in megacity. Shanghai J Prev Med 2015;5:248-55.

33. Toshie M, Tran TH, Doan ML, et al. Knowledge, attitudes, practices and emotional reactions among residents of avian influenza (H5N1) hit communities in Vietnam. PLOS ONE 2012;10:1-10.
34. Wachinger G, Renn O, Begg C, et al. The risk perception paradoximplication for governance and communication of natural hazards. Risk Anal 2013;33:1049-65.

35. Terpstra T, Lindell MK, Gutteling JM. Does communicating (flood) risk affect (flood) risk perceptions? Results of a quasi-experimental study. Risk Anal 2009;29:1141-55.

36. Biernacki W, Dzialek J, Padio T. Community attitudes towards extreme phenomena relative to place of residence and previous experience. In: Liszewski S, ed. The influence of extreme phenomena on the natural environment and human living conditions. 2008:207-37.

37. Botzen WJW, Aerts JCHJ, van den Bergh JCJM. Dependence of flood risk perceptions on socioeconomic and objective risk factors. Water Resour Res 2009;45:1-15.

38. Johannesdottir G, Gisladottir G. People living under threat of volcanic hazard in southern Iceland: vulnerability and risk perception. Nat Hazards Earth Syst Sci 2010;10:407-20.

39. Grothmann T, Reusswig F. People at risk of flooding: Why some residents take precautionary action while others do not. Nat Hazard 2006;38:101-20.

40. Chan EY, Kim JH, Lin C, et al. Is previous disaster experience a good predictor for disaster preparedness in extreme poverty households in remote Muslim minority based community in China. $\mathrm{J}$ Immigrant Minority Health 2014;16:466-72.

41. KAjihara $\mathrm{H}$, Kishimoto $\mathrm{A}$. Risk tradeoff analysis of substance substitution: scope, framework and metrics. Paper Presented as 3rd Integ-Risk Conference on New Technologies and Emerging Risks 7-8 June 2011, Stuttart, Germany.

42. Burningham K, Fielding J, Thrush D. "It'll never happen to me": understanding public awareness of local flood risk. Disasters 2008;32:216-38.

43. Qiu XX, Zheng QL, Xia LH. Application research of pneumoconiosis patients health education intervention by using KAP model. Chin Occup Med 2014:41:265-71.

44. Chen L, Wang Y, Liu Y. Content-Based Incentive Theory. Organizational Behavior. Beijing, BJ: People's Medical Publishing House, 2005:127. 